\title{
O papel da normalização nas publicações científicas
}

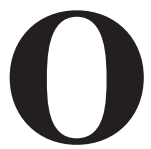

marco mais importante para a normalização da comunicação científica na área médica surgiu em 1978, em Vancouver, no Canadá, com o encontro de importantes editores de revistas médicas, que posteriormente se transformou no International Committee of Medical Editors Journals $(\mathrm{ICMJE})^{(1)}$ e passou a estabelecer padrões e requisitos para a comunicação médico-científica, hoje seguidos pela quase totalidade das revistas médicas. Outras entidades ${ }^{(2.5)}$ também disponibilizam diretrizes para orientar editores científicos e gestores de ciência e tecnologia em saúde na busca da melhor qualidade das publicações.

O conhecimento científico só pode ser considerado efetivamente existente na medida em que esteja publicado e que possa ser recuperado nos diversos contextos: Bases de dados, Buscadores (Scirus, Scopus, Google Scholar), Arquivos open access, etc.

A normalização, como atividade reguladora, unifica formatos, procedimentos, favorece e facilita o registro, a transferência das informações para os meios impressos e/ou eletrônicos e permite a recuperação mais efetiva de documentos em sistemas de informação, além de garantir uma padronização que facilita o uso e a disseminação de seu conteúdo.

Embora seja a qualidade do conteúdo que efetivamente determina a qualidade de uma revista científica, todas as instituições indexadoras e reguladoras de publicações científicas incluem a normalização como um dos critérios para registro e inclusão em suas bases de dados.

Dentre os principais aspectos que precisam ser considerados na normalização de uma publicação estão: os extrínsecos, os intrínsecos e a linguagem.

Os aspectos extrínsecos, relativos aos requisitos formais da apresentação física da publicação, envolvem a normalização das legendas, do sumário, do expediente, do registro ISSN, das instruções aos autores e da periodicidade. Para cada um desses itens há uma norma que deve ser obedecida em todos os fascículos, garantindo assim a identidade formal da revista e a recuperação de seus artigos. A diversidade de formatos e o uso excessivo de recursos gráficos dificultam a consolidação da revista, como publicação científica, desfavorecem sua reputação, onera a editoração e demanda mais tempo na correção final da revista.

Os aspectos intrínsecos se referem à normalização das citações no texto, à acurácia das referências dos documentos consultados, que devem garantir a acessibilidade e a credibilidade das fontes citadas, à padronização dos resumos, dos descritores e da identidade dos autores (nomes dos autores, titulação e afiliação institucional). Nessa questão, ressaltamos a importância da normalização dessas informações para os bancos de dados, como o Science Citation Index, que utiliza informações contidas em bases de dados bibliográficas para a construção dos indicadores de produção científica, constituídas fundamentalmente pelo conteúdo das publicações. Na base de dados da Literatura Latino-Americana em Ciências da Saúde (Lilacs) encontramos registros com diversos formatos do nome de um mesmo autor em diferentes publicações, constituindo uma limitação para a recuperação dessas publicações. Já na base de dados Medline, os nomes dos autores brasileiros com grau de parentesco (Neto, Junior, Sobrinho, Filho) somam cerca de 1.200 artigos com erros de registro, o que às vezes, para um autor, representa a totalidade das suas publicações.

Outro fator importante é a linguagem da publicação. É fundamental que a redação seja clara, concisa e obedeça as regras da língua em que está escrita ${ }^{(6-7)}$. Publicar na língua de origem ou em outra língua 
deve ser estimulado, mas em ambas, as regras devem ser corretamente empregadas. $\mathrm{O}$ uso de um bom dicionário e da gramática, a obediência à nomenclatura científica, à nomina anatômica e às normas e padrões oficiais de abreviaturas, são fatores que, combinados com os anteriores, darão credibilidade à revista, atingirão nível adequado para atrair a colaboração dos melhores pesquisadores nacionais e permitirão que sejam indexadas nas diversas fontes de referência existentes.

Edna Terezinha Rother

Bibliotecária, Editora Técnica de Publicações Científicas erother@uol.com.br

\section{REFERÊNCIAS}

1. International Committee of Medical Journal Editors. Uniform requirements for manuscripts submitted to biomedical journals: writing and editing for biomedical publication. Updated February 2006 [text on the Internet]. [cited 2007 Aug 20]. Available from: www.ICMJE.org

2. Committee on Publication Ethics [homepage on the Internet]. London: COPE, c200-2007. [cited 2007 Aug 20]. Available from: http://www.publicationethics.org.uk/

3. Council of Science Editors. Guide to promoting integrity in scientific journals. Reston (VA): Council Science of Editors; 2007.

4. WAME.org [homepage on the Internet]. London: World Association for Medical Editors; c2000-2007. [cited 2007 Aug 20]. Available from: http://www.wame.org/

5. Clinical Trails.gov [homepage on the Internet]. Bethesda: US National Library of Medicine; c1993 [updated 2004 Aug 6, reviewed 2006 Jan 26; cited 2007 Aug 16]. Available from: http://clinicaltrials.gov/ct/gui

6. Day RA. Cómo escribir y publicar trabajos científicos. $3^{\text {a }}$ ed. español. Washington: Organización Panamericana de la Salud; 2005 [Publicación Científica y Técnica, 598].

7. Day RA. Scientific english. A guide for scientists and other professionals. 2nd ed. Phoenix, AZ: Oryx Press; 1995. 